\title{
Bearing capacity of RC beams reinforced with high strength rebars and steel plate
}

\author{
Taras Bobalo ${ }^{1}$ Yaroslav Blikharskyy ${ }^{2, *}$, Rostyslav Vashkevich ${ }^{1}$, and Myhailo Volynets ${ }^{1}$ \\ ${ }^{1}$ Lviv Polytechnic National University, Department of Building Constructions and Bridges, 79013, \\ 6, Karpinskogo str., Lviv, Ukraine \\ ${ }^{2}$ Lviv Polytechnic National University, Department of Highways and Bridges, 79013, \\ 6, Karpinskogo str., Lviv, Ukraine
}

\begin{abstract}
Nowadays, reducing the material content of not only buildings and structures in general, but also individual constructions is a topical task that can be realized through the use of high-strength concrete and reinforcement, as well as with the use of external reinforcement. The concentrated location of sheet reinforcement on the external the most tense facets of steel and concrete structures increases the operating height of the cross-section, makes it possible to more effectively use the strength properties of steel in comparison with conventional reinforced concrete, and with the same bearing capacity to economize on expenses. Composite and monolithic reinforced concrete structures with external reinforcement are used in various construction sectors around the world. This contributed to the expansion of the use of reinforced concrete for special buildings of power-engineering and hydrotechnical construction. The technical and economic efficiency, as well as the possibility of using external rebar as formwork for monolithic concrete construction, have been proved. Therefore, there is a need for the study of structures with combined reinforcement, in which high rigidity of steel and concrete structures is combined with an effective use of high-strength reinforcing bars (rebar) without prior tension.
\end{abstract}

\section{Introduction}

The use of composite steel-concrete beams and other combined systems in construction provides for more efficient use of the characteristics of the strength of materials and increase the bearing capacity of structures [1-4]. The concentrated location of band reinforcement on the external facets of the structural intersections allows to reduce their mass, decrease the size of the cross-section compared to the reinforced concrete or to reduce the use of steel at the same height of the cross-section. However, there is a danger of corrosive effects [5], therefore, it is necessary to provide for a qualitative protection against the influence of the environment $[6,7]$.

The advantage of high-strength steels is their durability and crack resistance. This allows to reduce the amount of metal used in construction, without losing the reliability of

*Corresponding author: yaroslav.z.blikharskyy@lpnu.ua 
the structure $[8,9]$. When increasing the bearing capacity of reinforced concrete samples using high-strength rebar, it is also necessary to provide for the strength of sloping crosssections [10]. However, if it was not envisaged in the design, then there are ways to enhance them [11].

Moreover, in addition to strength, another important characteristic of such steel is its deformability. In order to exhaust excess deformability, high-strength reinforcement is usually used in pre-stressed reinforced concrete structures [12], but the pre-stressing of the bearing bars leads to additional costs and is difficult to do under normal conditions. Therefore, the use of combined reinforcement allows to find the optimal ratio of different types of steels, which will reduce the cost of metal, while ensuring compliance with requirements for the strength and deformability of such structures.

The study of the strength and deformability of composite steel-concrete beams using sheet external band reinforcement as well as high-strength rebar, is relevant in terms of expediency and practical application of such structures in construction.

\section{Research methodology}

\subsection{Test specimen description and material properties}

For the experiment, eight composite steel-concrete beams were made with a cross-section of $0.12 \times 0.24 \mathrm{~m}$, a calculated span of $2.4 \mathrm{~m}$, in which the adhesion of the external band reinforcement was provided with U-shaped anchors (Fig. 1, 2) welded to it.

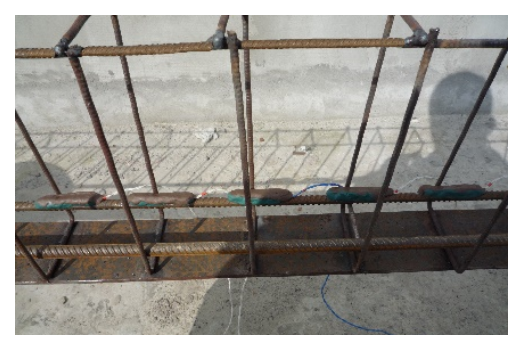

a)

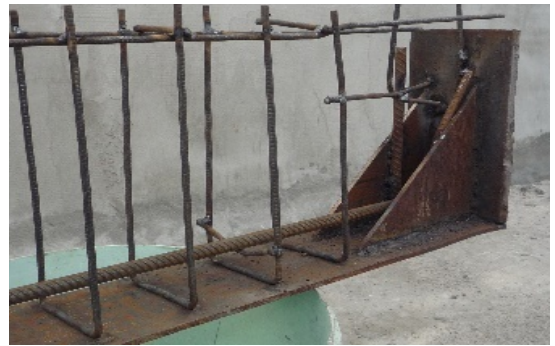

b)

Fig.1. Skeletons of steel-concrete experimental beams with adhesion of band reinforcement with concrete: a) view of the flexion area; b) view of the bearing area.

To reduce the absolute error, the study was conducted using twin beams, that is, two beams with the same reinforcement were made from the same batch of concrete. This approach made it possible to obtain qualitative output material for the experiment.

The concrete class was decided after testing concrete cubes of the size $150 \times 150 \mathrm{~mm}$, and prisms of $150 \times 150 \times 600 \mathrm{~mm}$. Thus, it was determined that the characteristic strength of the concrete corresponded to the class $\mathrm{C} 30 / 40-\mathrm{C} 35 / 45$. The calculated strength was accepted taking into account the coefficient of reliability $\gamma_{c}$, which for heavy concrete is 1.3. Concrete was made using Portland cement with the activity of M500 and superplasticizer HK-1 (BM) to facilitate the laying of the mixture, and to reduce the watercement ratio.

Notation for the beams was selected as follows: B - beam; I to IV - designation of the type of reinforcing skeleton; 1, 2 - serial number of the beam.

Compaction of concrete mix was vibrational. For all beams, the cross-reinforcement was adopted from the bars $\varnothing 5 \mathrm{~mm}$ of A240C class installed with a spacing of $70 \mathrm{~mm}$ in 
the zone of transverse forces acting on the support section (Fig. 1b), and with a spacing of $100 \mathrm{~mm}$ in the span (Fig. 1a).

The operating longitudinal reinforcement of the stretched zone was formed with smooth steel band rebar $\mathrm{C} 275$ of thickness $t=8 \mathrm{~mm}$, given that the adhesion with concrete was provided by U-shaped anchors, and with deformed reinforcement $\varnothing 10 \mathrm{~mm}$ of A1000 class. The made beams varied by different types of reinforcing skeleton and different ratios of band and bar reinforcement. Physical and mechanical characteristics of materials of the experimental beams are given in Table 1. Steel stretch was tested by the standard method, however the method using digital image correlation becomes more popular nowadays [13].

Table 1. Physical and mechanical characteristics of materials of the experimental beams.

\begin{tabular}{|c|c|c|c|c|c|}
\hline \multicolumn{2}{|c|}{ Notation of the beams } & $\begin{array}{l}\text { B - I - 1, } \\
\text { B - I - } 2\end{array}$ & $\begin{array}{l}\text { B - II - 1, } \\
\text { B - II - } 2\end{array}$ & $\begin{array}{l}\text { B - III - 1, } \\
\text { B - III - } 2\end{array}$ & $\begin{array}{l}\text { B - IV - 1, } \\
\text { B - IV - } 2\end{array}$ \\
\hline \multirow{3}{*}{ Heavy concrete } & $\begin{array}{c}f_{c k, \text { cube }} / f_{c k, p r i s m}, \\
\mathrm{MPa}\end{array}$ & $48.7 / 29.6$ & $46.3 / 28.1$ & $46.3 / 28.1$ & $49.2 / 29.9$ \\
\hline & $f_{c d}, \mathrm{MPa}$ & 22.8 & 21.6 & 21.6 & 23.0 \\
\hline & $E_{c m} \times 103, \mathrm{MPa}$ & 38.00 & 37.76 & 38.04 & 38.50 \\
\hline \multirow{5}{*}{$\begin{array}{l}\text { Reinforcement of } \\
\text { the stretched zone- } \\
\text { longitudinal band }\end{array}$} & $B_{s} \times t_{s}, \mathrm{~mm}$ & $82 \times 8$ & $46 \times 8$ & - & $114 \times 8$ \\
\hline & $f_{y k}, \mathrm{MPa}$ & 287 & 287 & - & 287 \\
\hline & $f_{y d}, \mathrm{MPa}$ & 273 & 273 & - & 273 \\
\hline & $E_{p} \times 10^{5}, \mathrm{MPa}$ & 2.05 & 2.05 & - & 2.05 \\
\hline & Brand & $\mathrm{C} 275$ & $\mathrm{C} 275$ & - & $\mathrm{C} 275$ \\
\hline \multirow{5}{*}{$\begin{array}{l}\text { Reinforcement of } \\
\text { the stretched zone- } \\
\text { longitudinal bar }\end{array}$} & $\varnothing, \mathrm{mm}$ & $1 \varnothing 10$ & $2 ø 10$ & $3 ø 10$ & - \\
\hline & $f_{y k}, \mathrm{MPa}$ & 1080 & 1080 & 1080 & - \\
\hline & $f_{y d}, \mathrm{MPa}$ & 900 & 900 & 900 & - \\
\hline & $E_{p} \times 10^{5}, \mathrm{MPa}$ & 1.85 & 1.85 & 1.85 & - \\
\hline & Class & A1000 & A1000 & A1000 & - \\
\hline \multirow{5}{*}{$\begin{array}{l}\text { Reinforcement of } \\
\text { the compressed } \\
\text { zone-longitudinal } \\
\text { bar }\end{array}$} & $\varnothing^{\prime}, \mathrm{mm}$ & 8 & 8 & 8 & 8 \\
\hline & $f_{y k}{ }^{\prime}, \mathrm{MPa}$ & 594.5 & 594.5 & 594.5 & 594.5 \\
\hline & $f_{y d}{ }^{\prime}, \mathrm{MPa}$ & 495 & 495 & 495 & 495 \\
\hline & $E_{p}{ }^{\prime} \times 10^{5}, \mathrm{MPa}$ & 2.05 & 2.05 & 2.05 & 2.05 \\
\hline & Class & A400C & A400C & A400C & A400C \\
\hline \multirow{4}{*}{$\begin{array}{l}\text { Bar cross- } \\
\text { reinforcement }\end{array}$} & $\varnothing, \mathrm{mm}$ & 5 & 5 & 5 & 5 \\
\hline & $f_{y w d}, \mathrm{MPa}$ & 296 & 296 & 296 & 296 \\
\hline & $E_{p} \times 10^{5}, \mathrm{MPa}$ & 2.05 & 2.05 & 2.05 & 2.05 \\
\hline & Class & A240C & A240C & A240C & A240C \\
\hline
\end{tabular}

For the reinforcement of beams, types of skeletons with different percentage reinforcement of the operating rebar of the lower stretched zone were used. The main task for the layout of skeleton type was to provide a close total tensile force that can be taken simultaneously by all the reinforcement of the stretched zone. Thus, in the skeleton type I, the total calculated tensile force taken by the reinforcement of the stretched zone was 2497.4 MPa, $68.8 \%$ of which was taken by the steel rebar C275 and $31.2 \%$ by the A1000 rebar. In the skeleton type II, the total calculated tensile force taken by the reinforcement of the stretched zone was $2417.6 \mathrm{MPa}, 38.1 \%$ of which was taken by the steel rebar C275 and $61.9 \%$ by the A1000 rebar. In the skeleton type III, only the reinforcement of A1000 class was used, and the calculated tensile force was $2119.5 \mathrm{MPa}$. In the skeleton type IV, 
only the reinforcement of C275 class was used, and the calculated tensile force was 2489.8 $\mathrm{MPa}$. Characteristics of the experimental beams is given in Table 2.

Table 2. Characteristics of the experimental beams.

\begin{tabular}{|c|c|c|c|c|c|}
\hline \multicolumn{2}{|c|}{ Notation of the beams } & $\begin{array}{l}\text { B - I - } 1, \\
\text { B - I - } 2\end{array}$ & $\begin{array}{l}\text { B - II - 1, } \\
\text { B - II - } 2\end{array}$ & $\begin{array}{l}\text { B - III - 1, } \\
\text { B - III - } 2\end{array}$ & $\begin{array}{l}\text { B - IV - 1, } \\
\text { B - IV - } 2\end{array}$ \\
\hline \multirow{3}{*}{$\begin{array}{l}\text { Beam cross- } \\
\text { section } \\
\text { parameters }\end{array}$} & width $b, \mathrm{~mm}$ & 120 & 120 & 120 & 120 \\
\hline & height $h, \mathrm{~mm}$ & 235 & 236 & 238 & 235 \\
\hline & area $A, \mathrm{~cm}^{2}$ & 282 & 283 & 286 & 282 \\
\hline \multicolumn{6}{|c|}{ Reinforcement of the stretched zone-longitudinal band of C275 class } \\
\hline \multicolumn{2}{|c|}{ Area $A s, \mathrm{~cm}^{2}$} & 6.56 & 3.68 & - & 9.12 \\
\hline \multicolumn{6}{|c|}{ Reinforcement of the stretched zone-longitudinal bar of A1000 class } \\
\hline \multicolumn{2}{|c|}{ Quantity and diameter of bars, $\mathrm{mm}$} & $\begin{array}{c}1 \varnothing 10 \\
\mathrm{~A} 1000\end{array}$ & $\begin{array}{c}2 ø 10 \\
\mathrm{~A} 1000\end{array}$ & $\begin{array}{c}3 ø 10 \\
\mathrm{~A} 1000 \\
\end{array}$ & - \\
\hline \multicolumn{2}{|c|}{ Area $A s, \mathrm{~cm}^{2}$} & 0.785 & 1.570 & 2.355 & - \\
\hline \multicolumn{2}{|c|}{$\begin{array}{c}f_{y k} \cdot A_{s}, \text { A } 1000 \\
f_{y k} \cdot A_{s}, \text { of a sheet } \\
\end{array}$} & $\begin{array}{l}31.2 \% \\
68.8 \%\end{array}$ & $\begin{array}{l}61.9 \% \\
38.1 \%\end{array}$ & $\begin{array}{c}100 \% \\
0 \%\end{array}$ & $\begin{array}{c}0 \% \\
100 \%\end{array}$ \\
\hline \multicolumn{2}{|c|}{$\begin{array}{c}\text { Total percentage of reinforcement } \\
\text { by operating rebar }\end{array}$} & $2.77 \%$ & $1.97 \%$ & $0.89 \%$ & $3.45 \%$ \\
\hline
\end{tabular}

\subsection{Experimental program}

A peculiarity of the experiment was that with different percent reinforcement by the operating rebar in the lower zone from $0.89 \%$ to $3.45 \%$, all experimental samples were designed equal, that is, the destructive load for them, according to the calculation of strength was the same. This was ensured by different ratio of areas between the band reinforcement made of steel plate $\mathrm{C} 275$ class and the high-strength reinforcement of A1000 class. The beams of types B-III and B-IV were adopted as reference, without combined reinforcement, they have one class reinforcement for the operating rebar of the lower zone. The B-III beam in the lower stretched zone was reinforced only with A1000 class reinforcement, and the B-IV beam was reinforced only with steel plate $\mathrm{C} 275$ class.

The loading of the experimental beams was carried out by stages of $10 \%$ of the destructive calculated according to [14], carried out with the help of a hydraulic jack with a power of $1000 \mathrm{kN}$. Through the distributive traverse, force was applied to the top surface of the beam in the form of two concentrated forces applied symmetrically to the middle of the beam at a distance from the supports $1 / 3$ of the span. The loading time at each stage was 30 minutes, after which the device readings were taken.

\section{Results of the experimental study}

\subsection{Bearing capacity of experimental beams}

The onset of the flow started earlier for the band reinforcement than for high-strength reinforcement. This was accompanied by an increase in the growth of deformations and deflections in the subsequent loading of the beam.

When the flow of the band reinforcement was achieved, the tension in it did not decrease, but it continued to take the load during the flow, with the constant tensile force 
$f_{y k} \times A_{s(\text { band })}$. Strengthening of the band reinforcement after passage of the site of flow was not achieved, because of the considerable length of this area in the diagram of band steel stretch.

The bending moment corresponding to the flow tension in the band reinforcement was conventionally indicated $M_{d r l}$, and the moment corresponding to the conditional flow of the high-strength rebar was called the "marginal moment" $M_{d r 2}$.

Since the calculation of the strength of the bending structures is carried out in terms of marginal state, then at the basis of the further analysis was laid the "marginal moment" $M d r 2$, which corresponds to the onset of the flow in high-strength rebar.

The reliability coefficient $\gamma_{s}$ for A1000 class reinforcement according to [14] was $\gamma_{s}-1.2$, for band reinforcement C275 $\gamma_{s}-1.05$.

The results of the experiment are presented in Table 3.

Table 3. Results of the experimental study.

\begin{tabular}{|c|c|c|c|c|c|c|c|c|c|}
\hline \multirow[b]{2}{*}{$\begin{array}{l}\text { Notation } \\
\text { of the } \\
\text { beams }\end{array}$} & \multirow{2}{*}{$\begin{array}{l}* \text { Exp. } \\
M_{d r l}, \\
\mathrm{kNm}\end{array}$} & \multirow{2}{*}{$\begin{array}{l}* \text { Th. } \\
M_{d r l}, \\
\mathrm{kNm}\end{array}$} & \multirow{2}{*}{$\begin{array}{l}\text { Exp. } \\
\text { defle } \\
\text { ction, } \\
\mathrm{mm}\end{array}$} & \multirow{2}{*}{$\begin{array}{l}\text { Th. } \\
\text { defle } \\
\text { ction, } \\
\mathrm{mm}\end{array}$} & \multicolumn{3}{|c|}{$\begin{array}{c}\text { Bearing capacity, } \\
\mathrm{kNm}\end{array}$} & \multicolumn{2}{|c|}{ Deviation, $\%$} \\
\hline & & & & & $\begin{array}{l}\text { Exp. } \\
M_{d r 2}, \\
\mathrm{kNm}\end{array}$ & \begin{tabular}{|c|} 
Th. \\
$M_{\max }^{D B N}$, \\
$\mathrm{kNm}$
\end{tabular} & $\begin{array}{l}* * \mathrm{Th} . \\
M^{D B N}, \\
\mathrm{kNm}\end{array}$ & $\begin{array}{c}\left(M_{d r 2^{-}}\right. \\
\left.M^{D B N}\right) / M_{d r 2} \\
\%\end{array}$ & $\begin{array}{c}* *\left(M_{d r 2^{-}}\right. \\
\left.M^{D B N}\right) / M_{d r 2} \\
\%\end{array}$ \\
\hline B - I - 1 & 42.70 & \multirow{2}{*}{39.9} & 6.87 & \multirow{2}{*}{6.71} & 51.52 & \multirow{2}{*}{51.38} & \multirow{2}{*}{46.39} & 0.3 & 10.0 \\
\hline B - I - 2 & 43.60 & & 7.98 & & 52.64 & & & 2.4 & 11.9 \\
\hline B - II - 1 & 31.10 & \multirow{2}{*}{27.2} & 8.01 & \multirow{2}{*}{10.6} & 55.20 & \multirow{2}{*}{52.10} & \multirow{2}{*}{46.95} & 5.6 & 14.9 \\
\hline B - II - 2 & 31.10 & & 7.36 & & 52.40 & & & 0.6 & 10.4 \\
\hline B - III - 1 & - & \multirow[b]{2}{*}{-} & - & & 55.36 & \multirow{2}{*}{52.85} & \multirow{2}{*}{47.82} & 4.5 & 13.6 \\
\hline B - III - 2 & - & & - & & 57.04 & & & 7.3 & 16.2 \\
\hline B - IV - 1 & 51.49 & \multirow{2}{*}{50.25} & 7.91 & \multirow{2}{*}{5.39} & 51.49 & \multirow{2}{*}{50.25} & \multirow{2}{*}{49.79} & 2.4 & 3.3 \\
\hline B - IV - 2 & 50.57 & & 6.72 & & \begin{tabular}{|l|}
50.57 \\
\end{tabular} & & & 0.6 & 0.6 \\
\hline
\end{tabular}

Exp. - experimental, th. - theoretical according to DBN B.2.6-98:2009 [14];

*moment at yielding of steel rebar;

**bearing capacity with the use ofreliability coefficients for materials $\gamma_{s,} \gamma_{c}$.

For the beam B-I-1, B-I-2, the percentage of beam reinforcement was $2.77 \%$. The flow of the band reinforcement was achieved at load $M_{d r l}=42.7 \mathrm{kNm}$ and $43.6 \mathrm{kNm}$. The flow of the high-strength rebar was achieved at the bending moment $M_{d r 2}=51.52 \mathrm{kNm}$ for the beam B-I-1, and $52.64 \mathrm{kNm}$ for B-I-2.The theoretical calculation assumed the magnitude of the destructive torque $M_{\max }^{D B N}=51.38 \mathrm{kNm}, M^{D B N}=46.39 \mathrm{kNm}$. Thus, the margin of safety when using the calculated characteristics of materials for this series is $10.0-11.9 \%$.

For the beam B-II-1, B-II-2, the percentage of beam reinforcement was $1.97 \%$. The flow of the band reinforcement was achieved at load $M_{d r l}=31.1 \mathrm{kNm}$. The flow of the highstrength rebar was achieved at the bending moment $M_{d r 2}=55.2 \mathrm{kNm}$, for the beam B-II- 1 , and $52.40 \mathrm{kNm}$ for B-II-2.The theoretical calculation assumed the magnitude of the destructive torque $M_{\max }^{D B N}=52.10 \mathrm{kNm}, M^{D B N}=46.95 \mathrm{kNm}$. Thus, the margin of safety when using the calculated characteristics of materials for this series is $10.4-14.9 \%$.

For the beam B-III-1, B-III-2, the percentage of beam reinforcement was $0.89 \%$. The flow of the high-strength rebar was achieved at the bending moment $M_{d r 2}=55.36 \mathrm{kNm}$, for the beam B-III-1, and $57.04 \mathrm{kNm}$ for B-III-2. The theoretical calculation assumed the 
magnitude of the destructive torque $M_{\max }^{D B N}=52.85 \mathrm{kNm}, M^{D B N}=47.82 \mathrm{kNm}$. Thus, the margin of safety when using the calculated characteristics of materials for this series is $13.6-16.2 \%$.
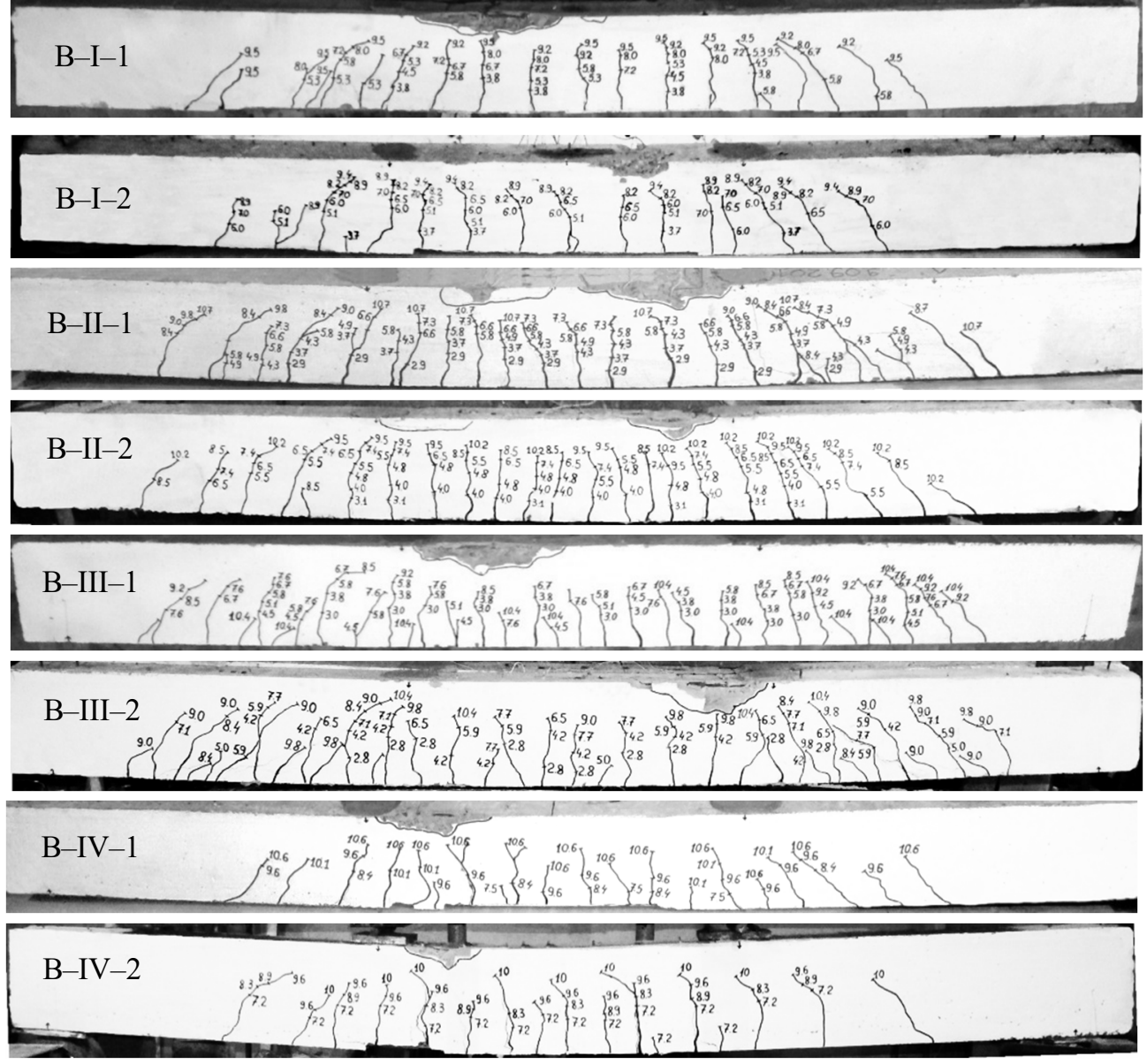

Fig. 2. Destruction pattern of the experimental beams.

For the beam B-IV-1, B-IV-2, the percentage of beam reinforcement was $3.45 \%$. The flow of the band reinforcement was achieved at load $M_{d r l}=51.49 \mathrm{kNm}$ for the beam B-IV-1, and $50.57 \mathrm{kNm}$ for B-IV-2.The theoretical calculation, according to [12], assumed the magnitude of the destructive torque $M_{\max }^{D B N}=50.25 \mathrm{kNm}, M^{D B N}=49.79 \mathrm{kNm}$. Thus, the margin of safety when using the calculated characteristics of materials for this series is $0.6-3.3 \%$.

From the results of the research, it follows that the current regulatory instrument DBN B.2.6-98: 2009 [14], when using the characteristic values of the strength of materials, allows to estimate with sufficient accuracy the strength of both composite steelconcrete reinforcement and reinforced concrete. Deviation from the experimental data does not exceed $7.3 \%$.

Composite steel-concrete beams which have a higher percentage of high-strength rebar, compared with the calculation using the reliability coefficients for materials $\gamma_{s}, \gamma_{c}$, have a greater margin of safety. Thus, in composite steel-concrete beams without the high- 
strength rebar, the margin of safety was up to $3.3 \%$.In the beams where the percentage of reinforcement with high-strength rebar was $31.2 \%$, the margin of safety was within the range of $10.0-11.9 \%$. With a percentage of high-strength rebar on the level $61.9 \%$, the safety margin was $10.4-14.9 \%$. In reinforced concrete beams reinforced only by highstrength rebar of class A1000, the safety margin was $13.6-16.2 \%$.

In reinforced concrete beams reinforced only by high-strength rebar's of class A1000, the safety margin was $13.6-16.2 \%$.

\section{Conclusions}

According to the results of experimental and theoretical studies, it has been established that the beams with combined reinforcement by high-strength and ordinary steel, after the flow of less stable reinforcement, continue to take the load until a conditional margin of safety for the high-strength rebar is reached. With a decrease in the percentage of highstrength rebar, the deformability of the beam also decreases, but the percentage of reinforcement increases at constant bearing capacity.

The performed experimental and theoretical studies of the work of the stress-strain state of structures allowed to determine that, when using combined reinforcement by steel concrete beams with a span of $2.4 \mathrm{~m}$, the optimal percentage of reinforcement with highstrength rebar of class A1000 is achieved, provided that $25-55 \%$ of tensile force is transferred on it. This reduces the percentage of reinforcement by $15-30 \%$ correspondingly, while ensuring compliance with requirements for deformability, crack resistance and durability.

\section{References}

1. Lu, Y \& Hu, L \& Liang, H \& Li, W. Journal of Building Engineering (2015)

2. Thamrin, Rendy. Matec Web of Conferences. 103 (2016)

3. Y. Blikharskyy, R. Khmil, Z. Blikharskyy. Matec Web of Conferences. 174 (2018)

4. P. Krainskyi, Y. Blikharskyy, R. Khmil, Z. Blikharskyy. Matec Web of Conferences. 183 (2018)

5. J. Selejdak, R. Khmil, Z. Blikharskyy. Matec Web of Conferences. 183 (2018)

6. Gene Corley, W. MP, 34 (1995)

7. Abbas Abdulsada, Shaymaa \& Al-Mosawi, Ali \& Amer, Ali. Biopr. Eng. 1 (2017)

8. Yoon, Seok-Kwang \& Lee, Su-Chan \& Lee, Do-Hyeong \& Lee, Jung-Yoon.. J Korea Concr. Inst., 26 (2) (2014)

9. Dios Garay, Juan \& Lubell, Adam. ASCE (2008)

10. P. Vegera, R. Vashkevych, Z. Blikharskyy. Matec Web of Conferences. 174 (2018)

11. Z. Blikharskyy, R. Khmil, P. Vegera. Matec Web of Conference. 116 (2017)

12. Li, J. CEt, 51 (2016)

13. Q. Zhang, Y. V. Mol'kov, Y. M. Sobko, Y. Z. Blikhars'kyi, R. E. Khmil. Materials Science, 50 (6) (2015)

14. National Standard of Ukraine, DBN B.2.6 - 98: 2009, 84 (2011) 